\title{
Mapping Patterns of Multiple Deprivation and Well-Being using Self-Organizing Maps: An Application to Swiss Household Panel Data
}

\author{
Mario Lucchini · Jenny Assi
}

Accepted: 9 April 2012/Published online: 7 July 2012

(C) Springer Science+Business Media B.V. 2012

\begin{abstract}
The aim of this paper is to propose multidimensional measures of deprivation and wellbeing in contemporary Switzerland, in order to overcome the limitations of standard approaches. More precisely, we have developed self organising maps (SOM) using data drawn from the 2009 Swiss Household Panel wave, in order to identify highly homogeneous clusters of individuals characterized by distinct profiles across 44 indicators of deprivation and well-being. SOM is a vector quantiser that performs a topology-preserving mapping of the $k$-dimensional input data to a two-dimensional, rectangular grid of output units, preserving as much as possible the information contained in the original input data. "Topology-preserving" means that, when an SOM is properly developed, units that are close in the output space are also close in the input space. Our results suggest that the SOM approach could improve our understanding of complex and multidimensional phenomena, like those of well-being, deprivation, vulnerability, that show only a partial overlapping with standard income poverty measures.
\end{abstract}

Keywords Well-being · Deprivation · Self-organizing map · Swiss Household Panel · Multidimensional measures

\section{Introduction}

This project seeks to contribute to the development of a conceptual and methodological framework for the identification of different forms of well-being and social deprivation in contemporary Switzerland. As known in the literature, most studies of well-being and

\footnotetext{
M. Lucchini $(\varangle) \cdot$ J. Assi

Department of Business and Social Sciences, University of Applied Sciences and Arts of Southern Switzerland, Palazzo E, 6928 Manno, Switzerland

e-mail: mario.lucchini@unimib.it

J. Assi

e-mail: jenny.assi@supsi.ch

M. Lucchini

Department of Sociology and Social Research, University of Milano-Bicocca, Milano, Italy
} 
deprivation are based on monetary indicators and synthetic indices, which capture only the economic-financial dimension of the phenomena, leaving out other, equally important dimensions such as health, relationships, emotional capital, and the degree of satisfaction with important aspects of daily life. Over the past three decades scholars and policy makers concerned with poverty and inequality have been making increasing use of abstract notions — such as 'social exclusion', 'fragility', 'vulnerability', 'well-being', 'quality of life', and 'happiness' - to represent processes and living conditions only partially inferable by means of monetary measures of 'poverty'.

One of the main goals of our paper is to propose an innovative analytical tool by which to represent the multidimensionality entailed in the concepts referred to above. Following research work already conducted in other European countries (cf. Whelan et al. 2010; Pisati et al. 2010; Lucchini et al. 2007), our aim is to develop Self-Organizing Maps (SOMs) applied to a complex set of non-monetary indicators of well-being and deprivation taken from the Swiss Household Panel (SHP). By employing this technique, we will try to identify a certain number of clusters of people characterised by different forms of wellbeing/deprivation, preserving as much as possible the information contained in the wide range of chosen indicators. The next step is to study the association between the identified prototypical forms of well-being/deprivation and some important heterogeneity factors, such as age, gender, level of education, income and region of residence.

After presenting the current state of research in the field of multidimensional well-being and deprivation, and we illustrate SOM functioning: a multidimensional complex of nonmonetary indicators are compressed onto a bi-dimensional plane, along which will be identified clusters of individuals characterized by a number of different life possibilities. The fourth chapter explains the data and the non-monetary indicators of deprivation on which we run the SOM procedure. Chapter 5 focuses purely on analyses. After having commented on the component planes, representing specialised graphs which are used to attribute a meaning to the micro-clusters identified, we propose reducing the output space to a smaller set of homogeneous regions or macro-clusters, in order to make the model more practical and easier to use for public policy implementation purposes. We then develop synthetic profiles for each macro-cluster across the nine dimensions underlying the indicators on which our analysis is based. Finally, in chapter 6 we test the capacity of some traditional social heterogeneity factors (such as level of education, income, age, region of residence) to influence macro-cluster membership.

\section{Current State of Research in the Field}

Academics who deal with 'poverty', 'well-being', 'deprivation', 'social exclusion' and, more generally, with social inequalities in the living conditions of individuals and families, have for a long time, and with increasing frequency, pointed out the difficulties in properly analyzing these topics through the sole use of monetary indicators (Sen 1981, 1985; Atkinson 1987; Nolan and Whelan 1996a, b, Saraceno 1990, 2002; Brandolini and D’Alessio 2002; Moiso 2005).

The definition and measurement of the constructs listed above are based on assessments which encounter some difficulties. In general, methodological disputes arise when deciding on the dimensions and indicators to adopt when assessing well-being and deprivation. These disputes stem from diverse philosophical conceptions about the meaning of equity and distributive justice. 
The definitional issues may lead to a different representation of the phenomena under investigation, and to a different interpretation of the related underlying causes; the same policy priorities may be revised with the adoption of different definitions (Atkinson 2000, p. 22).

According to the standard economic approach, poverty measurement entails a series of choices related to the monetary variables used (income, consumption, assets): the equivalence scales (OECD old scale, OECD modified scale etc.); the unit of analysis (the individual or the family); the temporal context of observation (the month, the year); and the methods for estimating and determining the thresholds at which to define who is poor and who is not $(50,60$ or $70 \%$ median threshold). These definitional issues are far from neutral and influence the results in one way or another. ${ }^{1}$

As is well known, measurements of 'absolute poverty' and 'relative poverty' identify a 'ridge' below which families or individuals are considered poor, or unable to meet a minimum level of basic needs considered as being socially acceptable. These measures of a monetary nature have the undoubted advantage of simplicity, but bring with them an excessive reduction of information and a high risk of errors in identifying people who are truly deprived. As noted in several empirical studies, there is a less than perfect overlap between income level and perceived degree of deprivation or well-being (Ringen 1988; Nolan and Whelan 1996a).

It should also be considered that in statistical surveys a high percentage of subjects do not respond to questions about earned income and, among those who do respond, many provide unreliable information. The statistics on monetary indicators may therefore be strongly biased. Furthermore, the proportion of people who are poor in income depends on the pattern of income distribution, and this dependency can lead to paradoxical results: the proportion of poor people can rise when both the mean and the variance of income distribution increase; on the other hand, this proportion can fall when both the mean and the variance of income distribution decrease.

Finally, families with equal numbers of equivalent adults, who receive the same income but who differ in terms of the physical health of component members, may experience dissimilar levels of deprivation or well-being (cf. Sen 1985).

In recent years social researchers have become increasingly interested in developing multidimensional measures of well-being/deprivation, social exclusion, quality of life, relational satisfaction and the like. Good health, an adequate income, support from a network of relationships, fulfilment of basic and secondary needs are regarded as the most important dimensions of well-being.

As mentioned above, the traditional measures of poverty are limited to quantifying the proportion of subjects falling below a certain income threshold in a given space-time context. These measures do not take into account the potential implications of a low income level on the living conditions of people. Scientists working in this domain are therefore becoming increasingly inclined to adopt the multidimensional concepts of 'social exclusion', 'deprivation', 'vulnerability' and 'weakness' in order to highlight the many relational and subjective aspects which are not fully expressed in monetary indicators (cf. Martinez and Huerta 2004; Heinzmann and Bergman 2010; Suter and Paris 2002).

One of the most fruitful multi-dimensional approaches on an international level is that of capabilities and functionings, proposed by Sen (1985), which leads us to rethink the analysis of inequality within a multi-dimensional "evaluative space". The multidimensional

1 For a better understanding of issues related to the measurement of economic poverty in the EU, see Atkinson (2000); Callan and Nolan (1991). 
approach shifts the focus from the level of adequacy of resources to the subjects' ability to transform resources into freely chosen purposes. In Sen's approach, the variables of income, consumption and assets have an instrumental relevance in the calculation of happiness since they allow individuals to choose what to do, which wishes to fulfil, and how to live their lives. It follows that monetary indicators, widely used in the measurement of economic poverty, only partially cover the semantic complexity of the concepts of Capabilities, Agency Commitment, Well-being, and Happiness.

Sen uses the term functionings to indicate the activities and conditions which characterize the existence of the subject. Some examples of functionings which have value for individuals are: enjoying good health, being well fed, being adequately dressed, knowing how to read and write, being fit enough to travel, being able to move freely, and participating in social activities. Capabilities, on the other hand, indicate the degrees of freedom of individuals, the real opportunities to decide whether and how to transform goods and resources into functionings (see Sen 1985).

Sen's approach has proven to be a harbinger of methodological developments and has stimulated important research work in the USA and Europe, where the extent of deprivation and well-being has been inferred on the basis of a series of items expressing the endowment of economic, human, relational, psychophysical and emotional capital (Muffels and Fouarge 2003; Whelan et al. 2002, 2010; Layte and Whelan 2002; Budowski et al. 2002; Pisati et al. 2010).

The classic concept of poverty is thus incorporated into concepts which refer to the denial of social rights of citizenship, the inability to take an active part in the various areas identified as socially relevant, and the difficulties faced by families and individuals in the transformation of resources into ability (Paugam 1996; Walker and Walker 1997; Byrne 1999; Negri 1990).

In particular, 'social exclusion' has been an important topic of investigation in the social sciences, at least since Runciman's (1966) contribution. In contemporary literature, 'social exclusion' is considered as the result of a multidimensional process leading to a state of precariousness, impoverishment of life, and being uprooted from social, economic and cultural networks, all of which are difficult to escape from (Paugam 1996; Sen 2000; Berghman 1995). Life cycle events such as family break-up, job loss, deterioration in health, and the loosening of social bonds all constitute processes which increase the risk of the transition from a state of relative advantage to one of relative disadvantage. Social exclusion therefore means a process of little or no participation in community life, the gradual marginalization of individuals and families, and a loosening of social cohesion (Burchardt et al. 2002).

The final outcome is the rejection of such descriptions, which then leads to the 'compression' of social issues into only two categories - the haves and the have nots - through which we lose sight of the many forms of 'vulnerability' which constitute intermediate states between cumulative well-being and poverty (Castel 1995, 1997).

'Vulnerability' both enriches and complicates the notion of economic poverty, in that it takes due consideration of temporary situations of malaise. The vulnerable person is one who experiences (or is at risk of experiencing) a silent deterioration of general living conditions caused either by the loss of employment, eradication from relational networks, or worsening health.

Complementary to the concepts of 'social exclusion' and 'vulnerability' is the construct of well-being. In recent years a true science of well-being has been delineated-one which has stimulated a substantial group of researchers from different disciplines. The concept of well-being has been an integral part of such concepts as the 'economics of happiness' or 'subjective well-being' (Kahneman 2007; Frey and Stutzer 2002; Brown 2004; Easterlin 
2001; Alesina et al. 2002), 'trust' (Luhmann 1979; Mutti 1998; Gambetta 1998), 'social capital' (Coleman 1990; Bourdieu 1980; Putnam 1993; Fukuyama 1995) and 'quality of life' (Cantril 1965; Allardt 1976; Andrews and Withey 1976).

The equation material resources equal well-being has been questioned by many scholars, who have noted that factors such as income, wealth, and consumption do not form a completely synonymous relationship with the complex emotional and cognitive conditions experienced firsthand, variously labelled as 'happiness', 'personal fulfilment', 'feeling good', and a 'sense of satisfaction and being fulfilled' (cf. Scitovsky 1976; Fuentes and Rojas 2001; Glatzer and Zapf 1984; Haller and Hadler 2006).

While multidimensional deprivation has been extensively studied in many western developed countries, there have been few empirical contributions in Switzerland to date. The research most commonly cited in the literature includes the work of Suter and Iglesias (2005), Tillmann and Budowski (2006), Gazareth and Suter (2010). These studies present synthetic indices obtained by combining a set of non-monetary indicators, which are weighted in accordance with some statistical criterion. Applying Halleröd's Proportional Deprivation Index $\left(\mathrm{PDI}^{2}\right)$ to Euromodule data, Suter and Iglesias (2005) estimated, in 2000 , that $31 \%$ of individuals had experienced one or more forms of deprivation. Using data from Swiss Household Panel (wave 1999) and a different composite index, Tillmann and Budowski (2006) estimated a percentage of $28 \%$ of deprived individuals. Gazareth and Suter (2010), calculating the Proportional Deprivation Index on nine items taken from the Swiss Household panel, found that between 1999 and $200746 \%$ of those interviewed had not experienced any form of deprivation. Finally, Ferro Luzzi et al. (2008) carried out a multidimensional study applying a factor and a cluster analysis to data from the first 5 waves (1999-2003) of the Swiss Household Panel. They used factor analysis to extrapolate the dimensions of the deprivation, and subsequently a hierarchical cluster analysis in order to identify homogenous groups of individuals with reference to the dimensions extrapolated, which are: 'financial poverty', 'poor health', 'bad neighbourhood' and 'social life'. Through the implementation of the cluster analysis they obtained a first very large cluster of individuals who are 'not poor' and a smaller second cluster of 'multidimensional poor'. 3 Further groups are considered as outliers, since they contain very few individuals. Our study replicates that of Luzzi et al. (2005) to some degree, although the technique adopted and some of the items utilized are different. Unlike Luzzi et al. (2005), our intention is not to classify individuals into broad categories (non-deprived individuals and deprived individuals), but to achieve a more precise segmentation in order to identify a broader range of prototypical forms of well-being and deprivation in contemporary Switzerland.

\section{The Analytic Strategy: The Application of Self-Organizing Maps (SOMs)}

In the last three decades social researchers have become increasingly interested in developing multidimensional measures of well-being and deprivation. Unfortunately, the more recent and more reliable multidimensional approaches also adhere to synthetic indices obtained by collapsing macro or micro indicators, so that the multidimensional nature of phenomena is at serious risk of disappearing. Other researchers who have studied deprivation and well-being from a multidimensional perspective have tried to reduce this

\footnotetext{
${ }^{2}$ For further details of the Proportional Deprivation Index see Halleröd (1995).

3 More specifically, the percentage of deprived individuals in the 1999 wave amounted to $4.38 \%$.
} 
complexity by means of factor, latent class and correspondence analysis and so on (Ferro Luzzi et al. 2008; De Wilde 2004, 2008; Moiso 2005; Whelan and Maître 2005, 2007; Nolan and Whelan 1996b). Using these approaches difficulties rising from spare observation in many cells, and the statistical assumptions underlying these data reduction techniques and that may have consequences for the empirical results of the analysis. As an alternative to standard techniques, which produce excessively crude images of the effective state of deprivation and well-being, we propose a nonparametric method with the highest investigative power, capable of intercepting the multi-dimensionality in a manner more congruent with reality. ${ }^{4}$

To obtain a low dimensional representation and visualization of high dimensional data, we utilise a Self Organizing Map (SOM), commonly also known as a Kohonen Map, which is one of the best-known unsupervised clustering procedures (Kohonen 1982, 2001). ${ }^{5}$

Self organising maps is an artificial neural network, and more technically a vector quantiser which performs a topology-preserving mapping of multi-dimensional input data $\mathbf{X}$ onto a usually two-dimensional, rectangular grid of output space-named units or nodes - each of which expresses a particular prototype vector or model $\mathbf{w}_{k}$. In a well developed SOM, each input vector or observation will be assigned to a specific SOM unit $k(k=1, \ldots, m)$, each of which is assigned a unique $1 \times d$ weight vector $\mathbf{w}_{k}$ which belongs to the same coordinate space as the input vectors $\mathbf{x}_{i}$-i.e., $\mathbf{w}_{k} \in \Re^{d}$. For this reason, each observation $i$ can be properly assigned to its best matching unit-i.e., to the SOM unit whose weight vector is closest to the input vector $\mathbf{x}_{i}$ in some metric.

Each node can be regarded as a pole of attraction, specialised to recognise specific observations which possess certain combinations of attributes. SOM units can also be seen as a set of convex regions which partition the input space so that every point in the input space is closer to the centroid of its region than to the centroid of any other region. 'Topology-preserving' means that, when a SOM is properly developed, units which are close in the output space are also close in the input space. The SOM model is very closely related to a $K$ means clustering algorithm, although there are two important differences which must be taken into due consideration and which make this tool better suited to preserving the information contained in multidimensional spaces. More specifically, while in the $K$ means clustering algorithm the number $K$ of clusters should be chosen according to the number of clusters in the data, in the SOM the number of reference vectors chosen can be much greater, irrespective of the number of clusters. The cluster structures will become visible at the end of the development process. Moreover, the SOM both performs clustering and organizes the clusters in a topological way. Unlike $K$ means, SOM can be used simultaneously, both for reducing the amount of data and for projecting it onto a lowdimensional display.

\section{Data and Variables}

The data used are drawn from the 2009 Swiss Household Panel (SHP) wave. SHP is a longitudinal survey started in 1999 and conducted within the framework of the Swiss

\footnotetext{
4 As has been recently proven in other papers (Lucchini et al. 2007; Pisati et al. 2010; Whelan et al. 2010), in comparison with latent class analysis, the SOM approach involves minimal assumptions and offers considerable additional discriminatory power for analysing the shape and form of social exclusion.

5 The term 'unsupervised clustering procedure' means that the groups of interest are not known a priori to the researcher and must be discovered by using an appropriate classification technique.
} 
Foundation for Research in Social Sciences (FORS). The importance of this survey is that it covers a wide range of sociologically relevant topics. We work with 5,956 subjects measured on 44 non-monetary indicators referring to the following dimensions: happiness, health, relational support, trust toward people and institutions, satisfaction with free time, housing, neighbourhood environment, material deprivation and financial problems.

In Table 1 we illustrate the dimensions, the indicators selected for each dimension, the type of measurement scale, the mean and the standard deviation related to each of the normalized indicators and the Cronbach's Alfa. More specifically, the first set of 7 items relates to happiness and emotional capital. This is followed by a set of 8 indicators focussing on health conditions, 4 items referring to social relations, 3 for trust toward people and institutions, 2 indicators of satisfaction with free time, 2 items concerning housing conditions and 3 items regarding neighbourhood environment. The last set of items refers to 9 indicators of basic deprivation and 6 indicators of savings and financial problems.

All indicators of deprivation have been rescaled so that a higher value corresponds to a worse situation. Moreover, each variable in the data set has been recalculated in accordance with the following formula: $\left[X_{\mathrm{i}}-\min \left(X_{i}\right)\right] /\left[\max \left(X_{i}\right)-\min \left(X_{i}\right)\right]$, where $X_{i}$ represents the original value of the variable, while $\min \left(X_{i}\right)$ and $\max \left(X_{i}\right)$ represent, respectively, the minimum and maximum values of the variable in question. This procedure allows variables to have differing means and standard deviations but equal ranges.

The polychoric correlation seen in Table 2 shows that the items forming one single dimension are strongly correlated with one another, particularly those referring to "happiness" and to "financial deprivation". The dimensions recording the lowest score on Cronbach's Alfa are "housing" and "relational support". The correlation between items that belong to different dimensions should also be noted: the "happiness" indicators seem particularly well correlated with those of "health", and the indicators of material deprivation are strongly related with those of financial deprivation. Finally, the housing condition items show the lowest level of correlation with the indicators belonging to the other dimensions.

\section{The Results}

The starting point of our analysis is a $5,956 \times 44$ matrix, corresponding to a multidimensional attribute space which is highly complex and equal to $\left(10^{21}+4^{1}+\right.$ $\left.3^{4}+2^{18}=1 E+21\right)$. This was compressed and projected onto a two-dimensional array consisting of 100 units or micro-clusters ordered into an rectangular grid with height $=10$ and width $=10$. Weight vectors were initialised using the linear method (Kohonen 2001) and the SOM development was conducted in two phases:

- a 10 epoch ordering phase, based on a large initial value and a rapid decrease in both the neighbourhood radius $(\sigma(1)=15, \sigma(10)=4$, linear decay function) and the learning rate $(\alpha(1)=1, \alpha(8)=0.1$, linear decay function).

- a 40 epoch fine tuning phase, based on a minute and slow adjustment of both the neighbourhood radius $(\sigma(1)=8, \sigma(40)=1$, linear decay function) and the learning rate $(\alpha(1)=0.1, \alpha(50)=0$, linear decay function). A Gaussian neighbourhood kernel was used in both development phases (Kohonen 1982, 2001).

At the end of the development process, each observation was allocated to its final best matching unit, and the quality of the SOM was assessed by means of the normalized 
Table 1 List of indicators of well-being and deprivation

\begin{tabular}{|c|c|c|c|}
\hline & Mean $^{\mathrm{a}}$ & SD & Alpha \\
\hline Happiness and Emotional Capital & & & 0.77 \\
\hline $\begin{array}{l}\text { (1) In general, how satisfied are you with your life? Scale } 0 \text { (not at all satisfied)-10 } \\
\text { (completely satisfied) }\end{array}$ & 0.20 & 0.13 & \\
\hline (2) How frequently do you generally experience joy? Scale 0 (never)-10 (always) & 0.26 & 0.13 & \\
\hline $\begin{array}{l}\text { (3) How frequently do you generally experience anger? Scale } 0 \text { (never)-10 } \\
\text { (always) }\end{array}$ & 0.40 & 0.19 & \\
\hline $\begin{array}{l}\text { (4) How frequently do you generally experience sadness? Scale } 0 \text { (never)-10 } \\
\text { (always) }\end{array}$ & 0.33 & 0.19 & \\
\hline $\begin{array}{l}\text { (5) How frequently do you generally experience anxiety? Scale } 0 \text { (never)-10 } \\
\text { (always) }\end{array}$ & 0.29 & 0.22 & \\
\hline $\begin{array}{l}\text { (6) Do you often have negative feelings such as having the blues, being desperate, } \\
\text { suffering from anxiety or depression? Scale } 0 \text { (never)-10 (always) }\end{array}$ & 0.21 & 0.20 & \\
\hline $\begin{array}{l}\text { (7) Are you often plenty of strength, energy and optimism? Scale } 0 \text { (never)-10 } \\
\text { (always) }\end{array}$ & 0.28 & 0.16 & \\
\hline Health & & & 0.61 \\
\hline $\begin{array}{l}\text { (8) How satisfied are you with your state of health? scale } 0 \text { (not at all satisfied)-10 } \\
\text { (completely satisfied) }\end{array}$ & 0.22 & 0.18 & \\
\hline $\begin{array}{l}\text { (9) Since last year, has your health improved or worsened? Scale } 0 \text { (greatly } \\
\text { worsened)-10 (greatly improved) }\end{array}$ & 0.49 & 0.12 & \\
\hline $\begin{array}{l}\text { (10) During the last } 4 \text { weeks, have you suffered from bad back or lower back } \\
\text { problems? Scale } 1 \text { (not at all) } 2 \text { (somewhat) } 3 \text { (very much). }\end{array}$ & 0.28 & 0.34 & \\
\hline $\begin{array}{l}\text { (11) During the last } 4 \text { weeks, have you suffered from general weakness, weariness, } \\
\text { or lack of energy? Scale } 1 \text { (not at all) } 2 \text { (somewhat) } 3 \text { (very much). }\end{array}$ & 0.25 & 0.32 & \\
\hline $\begin{array}{l}\text { (12) During the last } 4 \text { weeks, have you suffered from difficulty in sleeping, or } \\
\text { insomnia? Scale } 1 \text { (not at all) } 2 \text { (somewhat) } 3 \text { (very much) }\end{array}$ & 0.21 & 0.32 & \\
\hline $\begin{array}{l}\text { (13) During the last } 4 \text { weeks, have you suffered from headaches or facial pains? } \\
\text { Scale } 1 \text { (not at all) } 2 \text { (somewhat) } 3 \text { (very much)? }\end{array}$ & 0.21 & 0.31 & \\
\hline $\begin{array}{l}\text { (14) Please tell me to what extent, generally, your health is an impediment in your } \\
\text { everyday activities, in your housework, your work or leisure activities? scale } 0 \\
\text { (not at all) } 10 \text { (a great deal) }\end{array}$ & 0.19 & 0.25 & \\
\hline $\begin{array}{l}\text { (15) Do you suffer from (have) any chronic (long standing) illness or condition } \\
\text { (health problem)? Dummy } 1 \text { (yes) } 0 \text { (no) }\end{array}$ & 0.36 & 0.48 & \\
\hline Relational Support & & & 0.34 \\
\hline $\begin{array}{l}\text { (16) If necessary, in your opinion, to what extent can your relatives or your children } \\
\text { provide you with practical help, this means concrete help or useful advice? Scale } \\
0 \text { (not at all)-10 (a great deal) }\end{array}$ & 0.28 & 0.23 & \\
\hline $\begin{array}{l}\text { (17) To what extent can your relatives or children be available in case of need and } \\
\text { show understanding, by talking with your for example? Scale } 0 \text { (not at all)-10 (a } \\
\text { great deal) }\end{array}$ & 0.22 & 0.20 & \\
\hline $\begin{array}{l}\text { (18) How satisfied are you with your personal relationships? Scale } 0 \text { (completely } \\
\text { satisfied) } 10 \text { (not at all satisfied) }\end{array}$ & 0.19 & 0.15 & \\
\hline $\begin{array}{l}\text { (19) Do you get help regularly from someone not part of your household, either for } \\
\text { housework, childcare, or care of elderly or handicapped persons living in your } \\
\text { household? Dummy } 1 \text { (yes) } 0 \text { (no) }\end{array}$ & 0.81 & 0.40 & \\
\hline Trust and satisfaction in people and institution & & & 0.65 \\
\hline $\begin{array}{l}\text { (20) Would you say that most people can be trusted or that you can't be too careful } \\
\text { in dealing with people? scale } 0 \text { (Most people can be trusted)-10 (Can't be too } \\
\text { careful) }\end{array}$ & 0.36 & 0.21 & \\
\hline
\end{tabular}


Table 1 continued

Mean ${ }^{\mathrm{a}}$ SD Alpha

(21) Overall, how satisfied are you with the way in which democracy works in our 0.39 country? Scale 0 (completely satisfied)-10 (not at all satisfied)

(22) How much confidence do you have in Federal Government? Scale 0 (full 0.46 confidence) 10 (no confidence)

Satisfaction with free time and leisure time activities

(23) How satisfied are you with the amount of free time you have? Scale 0

$0.27 \quad 0.24$ (completely satisfied)-10 (not at all satisfied)

(24) How satisfied are you with your leisure time activities? Scale 0 (completely

$0.22 \quad 0.19$ satisfied)-10 (not at all satisfied)

\section{Housing condition}

(25) Are you faced with accommodation too small? Dummy 1(yes) 0 (no)

(26) Are you faced with badly heated accommodation? Dummy 1(yes) 0 (no)

\section{Neighbourhood Environment Deprivation}

(27) Are you faced with noisy external environment? Dummy 1(yes) 0 (no)

(28) Are you faced with traffic and industry pollution? Dummy 1(yes) 0 (no)

(29) Are you faced with crime, violence or vandalism in the area? Dummy 1(yes) 0 (no)

\section{Material deprivation}

(30) Can't afford one week holiday away from home per year? Dummy 1(yes) 0 (no)

(31) Can't afford inviting friends at least once a month? Dummy 1(yes) 0 (no)

(32) Can't afford going to restaurant at minimum of once a month? Dummy 1(yes) 0 (no)

(33) Can't afford private car? Dummy 1(yes) 0 (no)

$0.02 \quad 0.16$

$0.12 \quad 0.32$

(34) Can't afford colour TV? Dummy 1(yes) 0 (no)

(35) Can't afford computer at home? Dummy 1(yes) 0 (no)

(36) Can't afford washing machine? Dummy 1(yes) 0 (no)

$0.01 \quad 0.08$

(37) Can't afford dishwasher? Dummy 1(yes) 0 (no)

(38) Can't afford going to dentist if needed? Dummy 1(yes) 0 (no)

$0.02 \quad 0.13$

Financial and saving deprivation

(39) How satisfied are you with the financial situation of your household? Scale $0 \quad 0.25$ (completely satisfied) - 10 (not at all satisfied)

(40) Overall how satisfied are you with your financial situation? Scale 0

$\begin{array}{ll}0.28 & 0.20 \\ 0.25 & 0.21 \\ 0.32 & 0.47 \\ 0.09 & 0.28 \\ 0.18 & 0.23\end{array}$
(completely satisfied)-10 (not at all satisfied)

(41) How do you manage on your household's current income? Scale 0 (very easily)-10 (with great difficulty)

(42) Can you save at least 400 frs monthly? Dummy 1(yes) 0 (no)

(43) Cant' afford savings into the 3rd pillar? Dummy 1(yes) 0 (no)

save money) 2(your household spends what it earns) 3(your household eats into its assets and savings) 4(your household gets into debts)

a Means and standard deviations have been computed on rescaled indicators ranging from 0 to 1

quantization error (Kohonen 2001), which is a measure of the SOM resolution and which corresponds to the average distance between each input vector $\mathbf{x}_{i}$ and its best matching unit; our SOM exhibits a normalized quantization error equal to 0.10 , meaning that-on 
Table 2 Polychoric correlations between the 44 non monetary indicators of deprivation (the numbering of the items follows that shown in Table 1)

\begin{tabular}{|c|c|c|c|c|c|c|c|c|c|c|c|c|c|c|c|c|c|c|c|c|c|}
\hline 1 & 2 & 3 & 4 & 5 & 6 & 7 & 8 & 9 & 10 & 11 & 12 & 13 & 14 & 15 & 16 & 17 & 18 & 19 & 20 & 21 & 22 \\
\hline 1,00 & & & & & & & & & & & & & & & & & & & & & \\
\hline 0,48 & 1,00 & & & & & & & & & & & & & & & & & & & & \\
\hline 0,23 & 0,12 & 1,00 & & & & & & & & & & & & & & & & & & & \\
\hline 0,35 & 0,23 & 0,43 & 1,00 & & & & & & & & & & & & & & & & & & \\
\hline 0,26 & 0,16 & 0,33 & 0,55 & 1,00 & & & & & & & & & & & & & & & & & \\
\hline 0,42 & 0,33 & 0,25 & 0,50 & 0,43 & 1,00 & & & & & & & & & & & & & & & & \\
\hline 0,38 & 0,41 & 0,17 & 0,29 & 0,24 & 0,46 & 1,00 & & & & & & & & & & & & & & & \\
\hline 0,41 & 0,29 & 0,13 & 0,25 & 0,20 & 0,37 & 0,40 & 1,00 & & & & & & & & & & & & & & \\
\hline 0,13 & 0,11 & $-0,00$ & 0,04 & 0,01 & 0,10 & 0,15 & 0,30 & 1,00 & & & & & & & & & & & & & \\
\hline 0,15 & 0,09 & 0,08 & 0,15 & 0,12 & 0,19 & 0,15 & 0,32 & 0,12 & 1,00 & & & & & & & & & & & & \\
\hline 0,30 & 0,20 & 0,18 & 0,27 & 0,26 & 0,41 & 0,36 & 0,38 & 0,12 & 0,24 & 1,00 & & & & & & & & & & & \\
\hline 0,21 & 0,15 & 0,10 & 0,24 & 0,22 & 0,32 & 0,22 & 0,24 & 0,09 & 0,19 & 0,34 & 1,00 & & & & & & & & & & \\
\hline 0,11 & 0,05 & 0,11 & 0,09 & 0,09 & 0,16 & 0,14 & 0,15 & 0,07 & 0,15 & 0,28 & 0,14 & 1,00 & & & & & & & & & \\
\hline 0,25 & 0,16 & 0,08 & 0,24 & 0,18 & 0,35 & 0,30 & 0,54 & 0,16 & 0,31 & 0,34 & 0,24 & 0,14 & 1,00 & & & & & & & & \\
\hline 0,14 & 0,12 & 0,06 & 0,10 & 0,04 & 0,23 & 0,19 & 0,47 & 0,11 & 0,24 & 0,15 & 0,16 & 0,07 & 0,40 & 1,00 & & & & & & & \\
\hline 0,12 & 0,14 & 0,02 & 0,01 & 0,01 & 0,03 & 0,12 & 0,10 & 0,02 & 0,05 & 0,01 & 0,05 & $-0,03$ & 0,09 & 0,12 & 1,00 & & & & & & \\
\hline 0,15 & 0,16 & 0,06 & 0,04 & 0,03 & 0,08 & 0,13 & 0,12 & 0,02 & 0,05 & 0,05 & 0,05 & 0,01 & 0,09 & 0,10 & 0,59 & 1,00 & & & & & \\
\hline 0,39 & 0,36 & 0,17 & 0,20 & 0,16 & 0,26 & 0,28 & 0,23 & 0,05 & 0,07 & 0,15 & 0,13 & 0,04 & 0,13 & 0,08 & 0,28 & 0,33 & 1,00 & & & & \\
\hline 0,02 & 0,01 & 0,02 & 0,01 & $\begin{array}{r}-0,02 \\
\end{array}$ & $-0,04$ & $-0,02$ & $-0,06$ & 0,01 & 0,01 & $-0,08$ & 0,01 & $-0,02$ & $-0,06$ & 0,05 & 0,01 & 0,02 & $-0,06$ & 1,00 & & & \\
\hline 0,17 & 0,15 & 0,14 & 0,14 & 0,18 & 0,12 & 0,11 & 0,13 & 0,02 & 0,12 & 0,12 & 0,11 & 0,05 & 0,11 & 0,03 & 0,08 & 0,10 & 0,17 & 0,09 & 1,00 & & \\
\hline 0,16 & 0,09 & 0,11 & 0,10 & 0,11 & 0,11 & 0,10 & 0,13 & 0,03 & 0,11 & 0,08 & 0,10 & 0,04 & 0,09 & 0,03 & 0,03 & 0,07 & 0,07 & 0,10 & 0,28 & 1,00 & \\
\hline 0,15 & 0,12 & 0,13 & 0,05 & 0,06 & 0,06 & 0,10 & 0,09 & 0,03 & 0,06 & 0,05 & 0,05 & 0,04 & 0,03 & 0,04 & 0,04 & 0,07 & 0,10 & 0,09 & 0,27 & 0,61 & 1,00 \\
\hline 0,20 & 0,15 & 0,15 & 0,04 & 0,10 & 0,10 & 0,10 & 0,07 & $-0,00$ & 0,01 & 0,19 & 0,00 & 0,15 & 0,05 & 0,10 & 0,01 & 0,06 & 0,18 & 0,10 & 0,03 & 0,02 & 0,08 \\
\hline 0,31 & 0,25 & 0,13 & 0,13 & 0,13 & 0,21 & 0,23 & 0,23 & 0,07 & 0,09 & 0,21 & 0,07 & 0,13 & 0,13 & 0.02 & 0,08 & 0,13 & 0,33 & $-0,09$ & 0,09 & 0,06 & 0,08 \\
\hline 0,10 & 0,05 & 0,06 & 0,03 & 0,06 & 0,09 & 0,07 & 0,05 & $-0,03$ & 0,07 & 0,14 & 0,08 & 0,09 & 0,02 & 0,05 & 0,04 & 0,07 & 0,11 & 0,03 & 0,04 & 0,04 & 0,02 \\
\hline 0,10 & 0,06 & 0,01 & 0,04 & 0,04 & 0,10 & 0,06 & 0,09 & 0,01 & 0,06 & 0,05 & 0,02 & 0,01 & 0,07 & 0,01 & 0,00 & 0,02 & 0,06 & 0,07 & 0,01 & $-0,00$ & $-0,04$ \\
\hline 0,13 & 0,06 & 0,06 & 0,07 & 0,09 & 0,06 & 0,07 & 0,07 & 0,03 & 0,05 & 0,09 & 0,09 & 0,06 & 0,05 & 0,06 & 0,03 & 0,05 & 0,09 & 0,05 & 0,10 & 0,07 & 0,08 \\
\hline 0,13 & 0,07 & 0,06 & 0,14 & 0,15 & 0,15 & 0,09 & 0,10 & 0,00 & 0,09 & 0,17 & 0,12 & 0,03 & 0,11 & 0,09 & 0,04 & 0,07 & 0,07 & 0,01 & 0,09 & 0,09 & 0,06 \\
\hline 0,08 & 0,04 & 0,07 & 0,08 & 0,12 & 0,05 & 0,02 & 0,07 & 0,03 & 0,06 & 0,07 & 0,09 & 0,08 & 0,06 & 0,10 & 0,02 & 0,03 & 0,09 & 0,02 & 0,12 & 0,05 & 0,07 \\
\hline 0,28 & 0,17 & 0,10 & 0,20 & 0,16 & 0,20 & 0,16 & 0,20 & 0,09 & 0,16 & 0,20 & 0,18 & 0,05 & 0,17 & 0,10 & 0,05 & 0,04 & 0,10 & 0,26 & 0,22 & 0,21 & 0,14 \\
\hline 0,29 & 0,17 & 0,13 & 0,26 & 0,24 & 0,23 & 0,14 & 0,15 & 0,03 & 0,14 & 0,17 & 0,18 & 0,07 & 0,14 & 0,08 & 0,05 & 0,08 & 0,14 & 0,29 & 0,23 & 0,18 & 0,14 \\
\hline 0,21 & 0,11 & 0,07 & 0,14 & 0,14 & 0,16 & 0,08 & 0,13 & 0,05 & 0,11 & 0,14 & 0,15 & 0,07 & 0,15 & 0,05 & 0,08 & 0,06 & 0,07 & 0,20 & 0,17 & 0,14 & 0,13 \\
\hline 0,23 & 0,12 & 0,02 & 0,16 & 0,08 & 0,19 & 0,17 & 0,15 & 0,04 & 0,07 & 0,15 & 0,07 & 0,11 & 0,14 & 0,16 & 0,01 & $-0,00$ & 0,10 & 0,15 & 0,05 & $-0,03$ & $-0,02$ \\
\hline 0,05 & 0,07 & 0,12 & 0,04 & $-0,02$ & 0,15 & 0,06 & 0,01 & $-0,08$ & 0,32 & 0,17 & 0,04 & $-0,04$ & 0,13 & 0,01 & $-0,04$ & 0,09 & $-0,08$ & 0,03 & $-0,02$ & 0,07 & 0,11 \\
\hline 0,25 & 0,15 & 0,01 & 0,23 & 0,16 & 0,21 & 0,16 & 0,12 & 0,09 & 0,24 & 0,14 & 0,03 & 0,04 & 0,18 & 0,12 & 0,05 & 0,11 & 0,15 & $-0,02$ & 0,23 & 0,10 & 0,05 \\
\hline 0,29 & 0,05 & 0,12 & 0,22 & 0,21 & 0,17 & 0,03 & 0,10 & $-0,02$ & 0,03 & 0,19 & 0,01 & $-0,04$ & 0,08 & 0,01 & 0,17 & 0,15 & 0,04 & 0,11 & 0,13 & 0,17 & 0,09 \\
\hline 0,21 & 0,13 & 0,14 & 0,24 & 0,13 & 0,23 & 0,17 & 0,20 & 0,05 & 0,14 & 0,19 & 0,06 & 0,09 & 0,13 & 0,20 & 0,02 & $-0,03$ & 0,10 & 0,17 & 0,15 & 0,15 & 0,12 \\
\hline 0,33 & 0,18 & 0,19 & 0,23 & 0,18 & 0,19 & 0,14 & 0,18 & 0,07 & 0,21 & 0,17 & 0,23 & 0,07 & 0,17 & 0,05 & 0,03 & $-0,02$ & 0,15 & 0,23 & 0,22 & 0,22 & 0,17 \\
\hline 0,39 & 0,19 & 0,11 & 0,18 & 0,19 & 0,21 & 0,15 & 0,17 & 0,01 & 0,11 & 0,17 & 0,09 & 0,06 & 0,13 & 0,04 & 0,03 & 0,07 & 0,17 & 0,17 & 0,18 & 0,19 & 0,16 \\
\hline 0,42 & 0,22 & 0,15 & 0,18 & 0,20 & 0,23 & 0,19 & 0,22 & 0,04 & 0,12 & 0,20 & 0,10 & 0,10 & 0,11 & 0,05 & 0,03 & 0,08 & 0,21 & 0,10 & 0,20 & 0,20 & 0,18 \\
\hline 0,35 & 0,17 & 0,10 & 0,20 & 0,26 & 0,21 & 0,14 & 0,18 & 0,02 & 0,12 & 0,18 & 0,11 & 0,04 & 0,16 & 0,06 & 0,03 & 0,06 & 0,15 & 0,14 & 0,21 & 0,20 & 0,14 \\
\hline 0,23 & 0,10 & 0,03 & 0,17 & 0,17 & 0,19 & 0,12 & 0,15 & 0,02 & 0,14 & 0,17 & 0,14 & $-0,02$ & 0,20 & 0,14 & 0,04 & 0,03 & 0,07 & 0,15 & 0,16 & 0,15 & 0,08 \\
\hline 0,25 & 0,13 & 0,06 & 0,17 & 0,17 & 0,21 & 0,13 & 0,13 & 0,03 & 0,11 & 0,16 & 0,10 & 0,06 & 0,11 & 0,05 & 0,01 & 0,01 & 0,10 & 0,24 & 0,18 & 0,12 & 0,08 \\
\hline 0,19 & 0,08 & 0,02 & 0,14 & 0,13 & 0,17 & 0,13 & 0,13 & 0,01 & 0,08 & 0,13 & 0,12 & $\begin{array}{l}-0,02 \\
-\end{array}$ & 0,16 & 0,12 & 0,06 & 0,05 & 0,07 & 0,12 & 0,08 & 0,10 & 0,06 \\
\hline 23 & 24 & 25 & 26 & 27 & 28 & 29 & 30 & 31 & 32 & 33 & 34 & 35 & 36 & 37 & 38 & 39 & 40 & 41 & 42 & 43 & 44 \\
\hline 1,00 & & & & & & & & & & & & & & & & & & & & & \\
\hline 0,49 & 1,00 & & & & & & & & & & & & & & & & & & & & \\
\hline 0,20 & 0,15 & 1,00 & & & & & & & & & & & & & & & & & & & \\
\hline 0,06 & 0,07 & 0,21 & 1,00 & & & & & & & & & & & & & & & & & & \\
\hline 0,05 & 0,03 & 0,16 & 0,20 & 1,00 & & & & & & & & & & & & & & & & & \\
\hline 0,01 & 0,02 & 0,22 & 0,05 & 0,62 & 1,00 & & & & & & & & & & & & & & & & \\
\hline 0,03 & $-0,02$ & 0,13 & 0,07 & 0,34 & 0,34 & 1,00 & & & & & & & & & & & & & & & \\
\hline 0,01 & 0,12 & 0,22 & 0,12 & 0,15 & 0,19 & 0,18 & 1,00 & & & & & & & & & & & & & & \\
\hline 0,08 & 0,15 & 0,26 & 0,02 & 0,20 & 0,21 & 0,23 & 0,69 & 1,00 & & & & & & & & & & & & & \\
\hline 0,07 & 0,10 & 0,26 & 0,05 & 0,13 & 0,15 & 0,14 & 0,65 & 0,74 & 1,00 & & & & & & & & & & & & \\
\hline$-0,02$ & 0,13 & 0,13 & 0,09 & 0,11 & 0,20 & 0,10 & 0,51 & 0,43 & 0,42 & 1,00 & & & & & & & & & & & \\
\hline 0,10 & 0,08 & 0,43 & 0,85 & $-0,88$ & 0,28 & 0,19 & 0,46 & 0,52 & 0,54 & 0,67 & 1,00 & & & & & & & & & & \\
\hline - 0,04 & 0,20 & 0,31 & 0,17 & 0,24 & 0,26 & 0,21 & 0,56 & 0,65 & 0,49 & 0,60 & 0,77 & 1,00 & & & & & & & & & \\
\hline 0,06 & 0,07 & 0,25 & 0,03 & 0,18 & 0,33 & 0,20 & 0,53 & 0,73 & 0,57 & 0,45 & 0,75 & 0,55 & 1,00 & & & & & & & & \\
\hline 0,05 & 0,15 & 0,42 & 0,08 & 0,31 & 0,39 & 0,19 & 0,63 & 0,62 & 0,44 & 0,58 & 0,72 & 0,64 & 0,73 & 1,00 & & & & & & & \\
\hline 0,09 & 0,18 & 0,23 & 0,18 & 0,24 & 0,24 & 0,15 & 0,67 & 0,63 & 0,48 & 0,42 & 0,81 & 0,50 & 0,58 & 0,63 & 1,00 & & & & & & \\
\hline 0,12 & 0,17 & 0,20 & 0,16 & 0,13 & 0,11 & 0,11 & 0,50 & 0,49 & 0,46 & 0,35 & 0,28 & 0,39 & 0,41 & 0,36 & 0,51 & 1,00 & & & & & \\
\hline 0,21 & 0,22 & 0,16 & 0,11 & 0,11 & 0,09 & 0,07 & 0,42 & 0,39 & 0,35 & 0,29 & 0,21 & 0,31 & 0,36 & 0,30 & 0,42 & 0,56 & 1,00 & & & & \\
\hline 0,09 & 0,15 & 0,20 & 0,15 & 0,13 & 0,13 & 0,12 & 0,51 & 0,52 & 0,49 & 0,33 & 0,30 & 0,41 & 0,47 & 0,41 & 0,51 & 0,76 & 0,53 & 1,00 & & & \\
\hline - 0,09 & 0,01 & 0,14 & 0,13 & 0,11 & 0,19 & 0,15 & 0,65 & 0,64 & 0,56 & 0,56 & 0,34 & 0,60 & 0,52 & 0,44 & 0,67 & 0,52 & 0,38 & 0,60 & 1,00 & & \\
\hline 0,09 & 0,11 & 0,32 & 0,12 & 0,10 & 0,19 & 0,12 & 0,61 & 0,59 & 0,58 & 0,55 & 0,50 & 0,52 & 0,65 & 0,56 & 0,58 & 0,46 & 0,39 & 0,49 & 0,65 & 1,00 & \\
\hline$-0,09$ & 0,01 & 0,10 & 0,13 & 0,08 & 0,14 & 0,11 & 0,45 & 0.49 & 0,43 & 0,34 & 0,39 & 0,30 & 0,39 & 0,36 & 0,51 & 0,44 & 0,32 & 0,52 & 0,76 & 0,46 & 1,00 \\
\hline
\end{tabular}


average-each element of the input vector differs from its corresponding best-matchingunit weight by $10 \%$ points. $^{6}$

In order to understand the configuration of the developed SOM, we visually inspected its component planes, a type of graph that illustrates the value taken by a given element of the weight vector $\mathbf{w}_{k}$ on each SOM unit. Component planes referring to some of the chosen indicators are shown in Fig. 1.

In each component plane graph, SOM units are classified into distinct groups: white units (hot units) 'specialise' in attracting 'greatly disadvantaged respondents', red units 'specialise' in attracting 'greatly advantaged respondents', yellow and orange units attract respectively quite disadvantaged and quite advantaged people.

An examination of the component planes referring to emotional capital and satisfaction with life shows that only a small portion of nodes are hot units, and they are highly concentrated in the upper left area of the map. So in this area there is a high probability of finding people who are profoundly unhappy and unsatisfied with their lives. Other indicators of emotional capital, such as feelings of worry, lack of optimism, and, in particular, the feeling of anger, show a greater discriminating power, activating nodes that are also concentrated in the central area of the map.

Component planes referring to dissatisfaction with health, chronic conditions and impediment in life activities display a common pattern of discrimination, with hot units concentrated in the upper part of the map. In particular, the indicators of weakness, headaches and insomnia activate hot units in the central region of the map.

Regarding the indicators of material and financial deprivation, we note a concentration of white units on the upper-left part of the map. However, those indicating financial deprivation demonstrate a greater discriminatory capacity than those indicating material deprivation, and therefore also a stronger map-penetration ability.

The indicators referring to the quality of the surrounding environment reveal a different discriminatory pattern and a slightly greater heterogeneity of location in the grid, with a relatively high concentration of white nodes in the central and lower areas. Regarding the pollution and vandalism indicators, we note a significant penetration in the upper left part as well.

The relational deprivation indicators reveal a concentration of white and yellow nodes in the upper left part of the map. An exception to this rule is the indicator of help in domestic work and caring duties by someone who is not part of the household, which activates white nodes in the lower right part of the map.

The indicators referring to housing deprivation and trust toward people and institutions also reveal a significant grouping of white and yellow nodes in the upper left part of the map. Finally, the nodes that express dissatisfaction with free time are concentrated in the central area of the map, and demonstrate a strong discriminating capacity.

Since a detailed examination of the 100 units or micro-clusters that make up the map would take an excessive length of time and would be difficult to use as an analytic support tool in Policy Maker decisions, it was decided to group each micro-cluster into larger clusters.

The starting point for this kind of analysis is a dataset of 44 clustering variables and 100 rows, each of which represents a specific weight vector. We ran a hierarchical divisive clustering technique (DIANA) in order to obtain 9 macro-clusters, internally highly homogenous thanks to the topological properties of the map (Fig. 2).

In order to provide a substantive interpretation of the macro-clusters, we look at the component mean deviations from sample means of which we give below some example (Figs. 3, 4).

\footnotetext{
${ }^{6}$ All the analyses reported in this paper, including SOM development and visualization, have been carried out using routines written in R programming language (http://cran.r-project.org $\backslash$ ).
} 
Fig. 1 Component planes corresponding to some of the well-being and deprivation indicators chosen

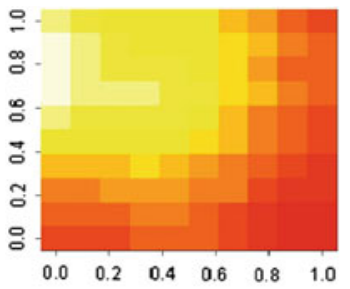

How frequently do you generally experience joy?

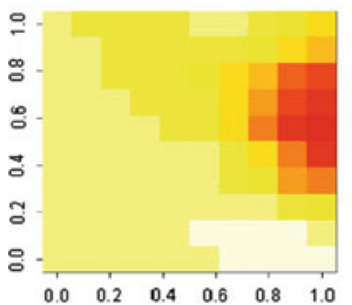

Do you get help regularly from someone not part of your household?

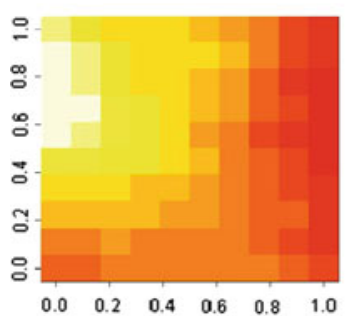

How much confidence do you have in Federal Government

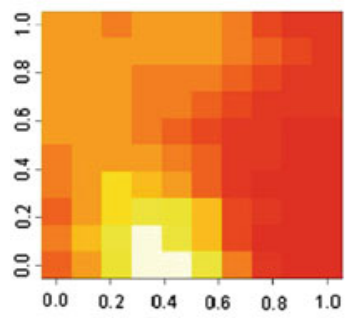

Are you faced with noisy external environment?

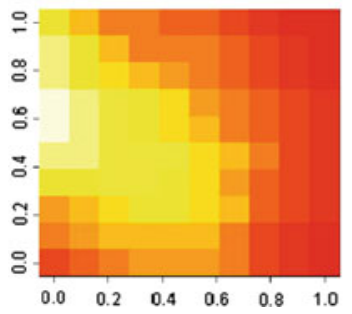

Are you faced with accommodation too small

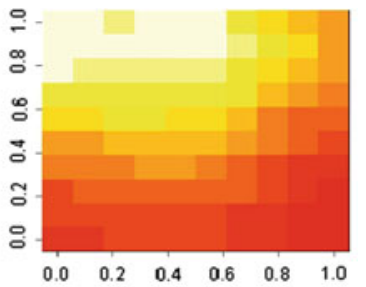

How satisfied are you with your state of health?

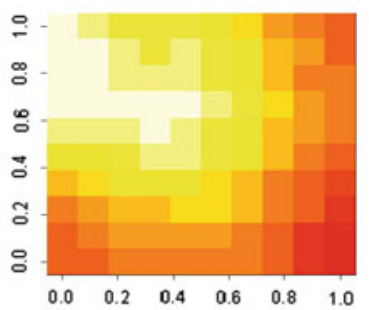

How satisfied are you with your personal relationship?

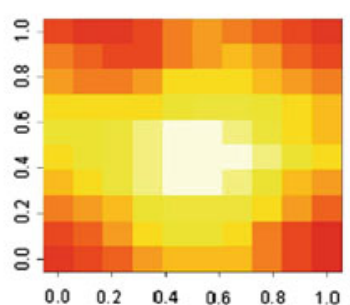

How satisfied are you with the amount of free time you have?

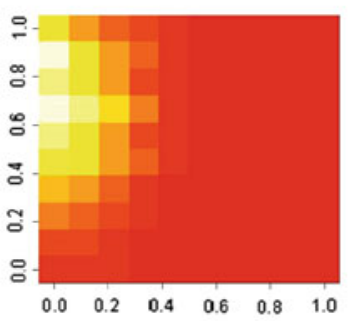

Can't afford one week holiday away from home per year?

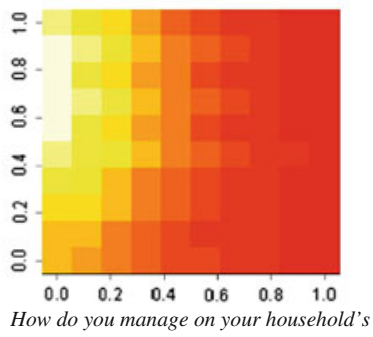
current income? 


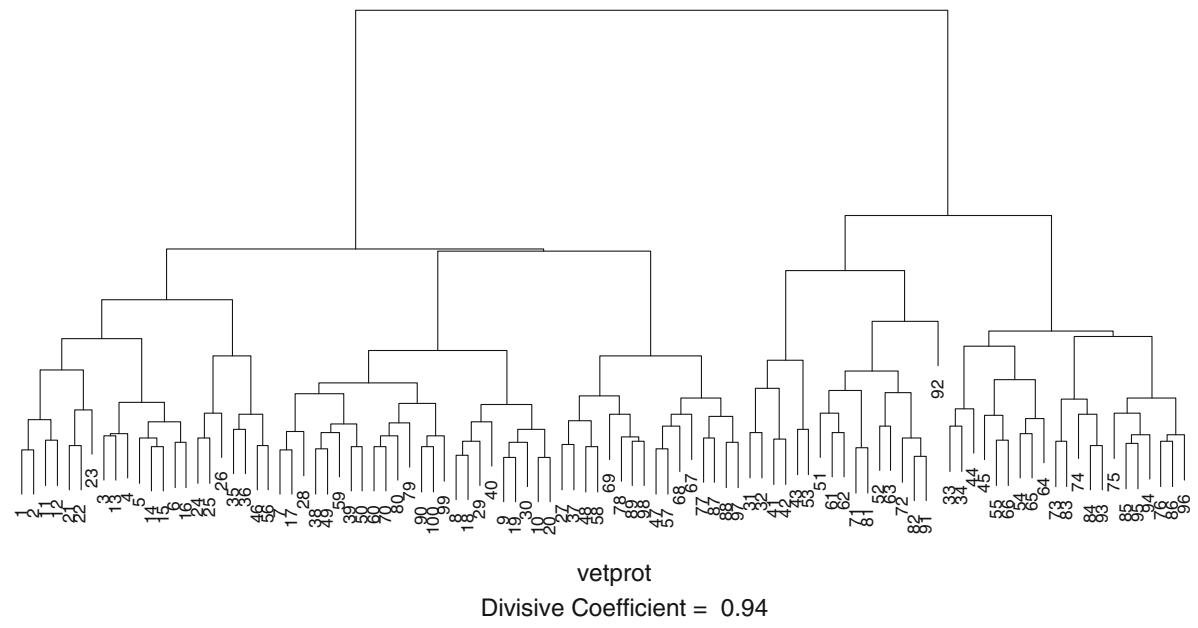

Fig. 2 DIANA hierarchical clustering technique

Finally, in the table below we give a synthetic description of the forms of deprivation and well-being related to the 9 macro-clusters. In developing these profiles, we have pursued a strategy developed by Pisati et al.(2010), seeking to synthesize the information given by each single indicator in a way that takes into account the strongly skewed distribution of almost all the indicators. Namely:

1. For each indicator $X_{j}(j=1, \ldots, 44)$, we have calculated its sample mean $\bar{x}_{j}$ and variance $V\left(X_{j}\right) ;^{7}$

2. For each indicator $X_{j}$, we have calculated three threshold values:

$$
\begin{aligned}
& t_{1 j}=\left|\ln \left(\frac{\bar{x}_{j}+V\left(X_{j}\right) \times 0.75}{\bar{x}_{j}}\right)\right| \\
& t_{2 j}=\left|\ln \left(\frac{\bar{x}_{j}+V\left(X_{j}\right) \times 1.5}{\bar{x}_{j}}\right)\right| . \\
& t_{3 j}=\left|\ln \left(\frac{\bar{x}_{j}+V\left(X_{j}\right) \times 2.25}{\bar{x}_{j}}\right)\right| .
\end{aligned}
$$

3. For each indicator $X_{j}$, we have calculated its mean within each cluster $C_{g}(g=1, \ldots, 9)$ : $\bar{x}_{j \mid g}$.

4. For each indicator $X_{j}$ and each cluster $C_{g}$, we have calculated the 'deviation' of the cluster-specific mean from the overall mean: $\delta_{j g}=\ln \left(\bar{x}_{j \mid g} / \bar{x}_{j}\right)$.

5. We have transformed the deviation values $\delta_{j g}$ into a corresponding set of discrete scores $s_{j g}$ in accordance with the following rules:

\footnotetext{
7 Indicators that appear as scales have been normalised.
} 


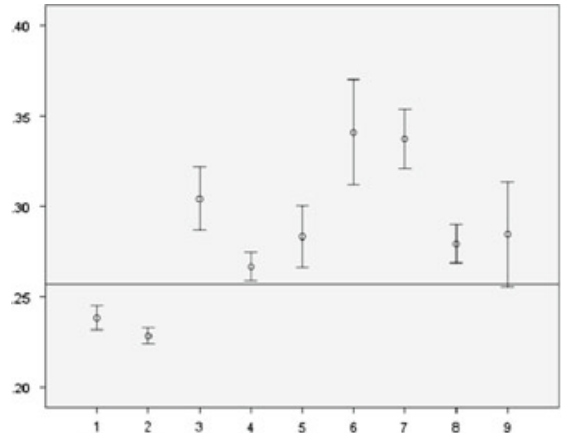

How frequently do you generally experience joy?

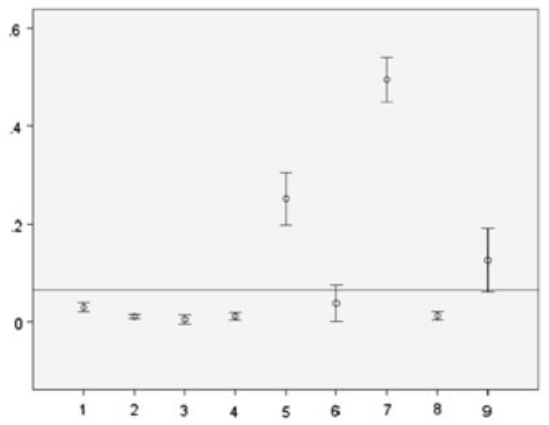

Can't afford one week holiday away from home per year?

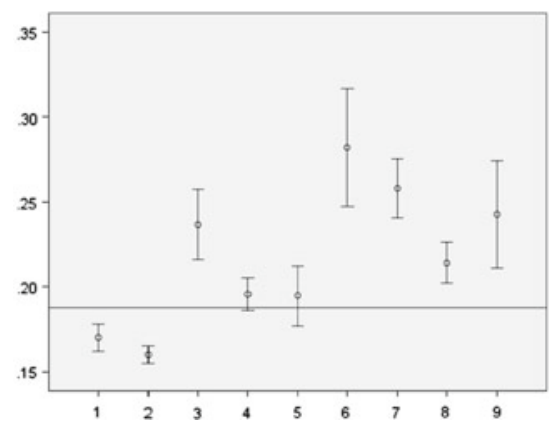

How satisfied are you with your personal relationship?

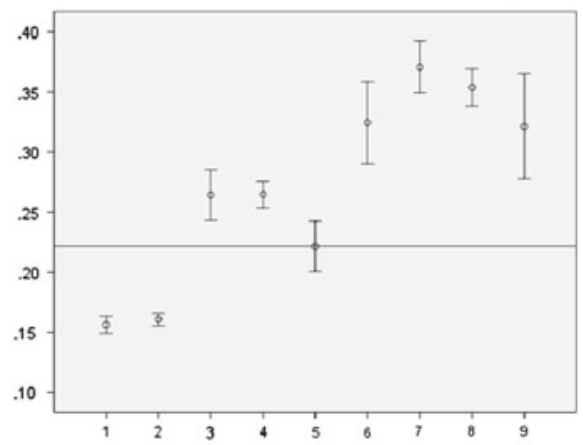

How satisfied are you with your state of health?

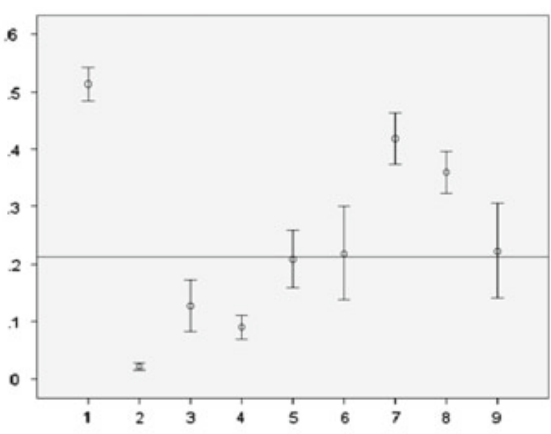

Are you faced with noisy external environment?

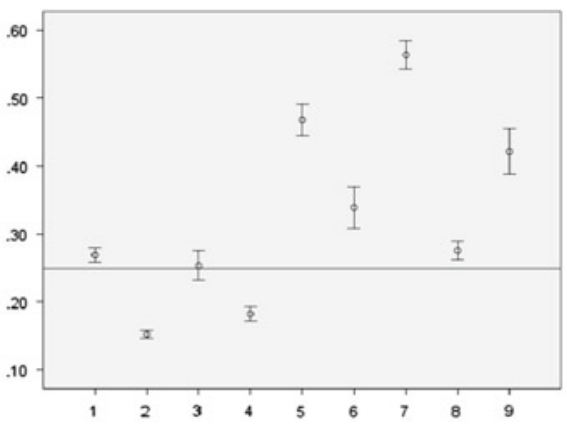

How do you manage on your household's current income?

Fig. 3 Component mean deviation of each indicator from sample mean

$$
s_{j g}=\left\{\begin{array}{r}
3 \text { if } \delta_{j g} \geq t_{3 j} \\
2 \text { if } t_{2 j} \leq \delta_{j g}<t_{3 j} \\
1 \text { if } t_{1 j} \leq \delta_{j g}<t_{2 j} \\
0 \text { if }-t_{1 j} \leq \delta_{j g}<t_{1 j} \\
-1 \text { if }-t_{2 j} \leq \delta_{j g}<-t_{1 j} \\
-1 \text { if }-t_{3 j} \leq \delta_{j g}<-t_{2 j} \\
-3 \text { if } \delta_{j g}<-t_{3 j}
\end{array}\right.
$$




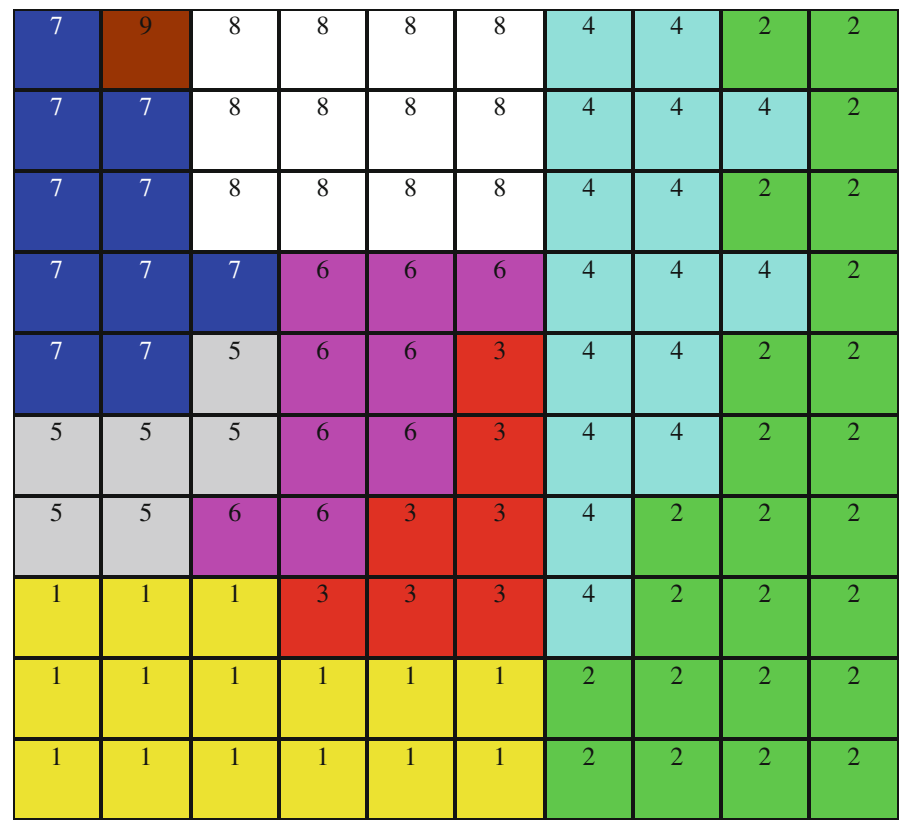

Fig. 4 Clustering of the SOM units

6. For each cluster $C_{\mathrm{g}}$ and each deprivation dimension $D_{q}(q=1, \ldots, 9)$, we have calculated the mean of the scores $s_{j g}$ pertaining to the relevant indicators:

$$
\mu_{g q}=\frac{\sum_{j \in D_{q}} s_{j g}}{\sum_{j=1}^{d}\left(j \in D_{q}\right)} .
$$

7. Finally, we have transformed the mean values $\mu_{g q}$ into a corresponding set of symbols in accordance with the following rules:

$$
\begin{aligned}
& \mu_{g q}<-2.5 \rightarrow \text { " }---, \\
& -2.5 \leq \mu_{g q}<-1.5 \rightarrow \text { " }- \text { - } \\
& -1.5 \leq \mu_{g q}<{ }^{\prime}{ }^{-}, 0.5 \rightarrow \text { " }- \text {, } \\
& -0.5 \leq \mu_{g q} \leq 0.5 \rightarrow \text { ' . }, \\
& 0.5<\mu_{g q} \leq 1.5 \rightarrow \text { " }+ \text { ", } \\
& 1.5<\mu_{g q} \leq 2.5 \rightarrow \text { " }++ \text { " } \\
& \mu_{g q}>2.5 \rightarrow \text { ' }+++ \text {, } .
\end{aligned}
$$

The end result of this procedure is shown in Table 3.

We now summarize the substantive interpretation of the 9 clusters identified:

- Cluster 1 comprises $19.7 \%$ of the sample and attracts people who tend to be happy, in good health, financially affluent, and unsatisfied only in reference to indicators for the quality of the surrounding environment (pollution, vandalism and noisy neighbourhood). Regarding the other dimensions, this cluster largely follows the average profile of the sample. 
- Cluster 2 is by far the best and largest group, comprising $38 \%$ of the sample, and displays a uniform pattern of well-being in all the dimensions. Hereunder it will be referred to as the cumulative well-being cluster.

- In Cluster 3, comprising $3.5 \%$ of the sample, we find people without any material or financial deprivation but who are extremely unhappy and unsatisfied with their leisure time. The people in this cluster show signs of vulnerability in reference to housing, health and social capital.

- Cluster 4 is characterized by people who are quite unhappy, unsatisfied with their health and with their free/leisure time. They do not generally suffer any financial or material deprivation, or any housing or environmental problems. This cluster comprises $12 \%$ of the sample.

- Cluster 5 contains $4.4 \%$ of the sample and is characterized by unhappy people, with low levels of confidence towards institutions, who are unsatisfied with their leisure/free time, with severe economic deprivation and some housing problems. In terms of health, relational support and environmental quality, they do not differ significantly from the sample average.

- Cluster 6 comprises only $1.8 \%$ of the sample and displays a pattern of deprivation in all the dimensions, with the exception of the economic dimension, where the average profile is recorded.

- Cluster 7 records the worst results, and displays a uniform pattern of deprivation in all the dimensions. It contains $7.7 \%$ of the sample and hereunder will be referred to as the cumulative or multiple deprivation cluster.

- In cluster 8 we find people who are quite unhappy, in chronic ill-health, hampered in daily life activities and with neighbourhood problems but in a condition of material and financial well-being. This cluster attracts $11 \%$ of the sample.

- Cluster 9 is a very small cluster that contains only $1.7 \%$ of the sample. People in this group are satisfied with their leisure/free time but are quite unhealthy, unsatisfied with their life and with housing, relational and environmental problems.

\section{Description of the Prototypical Forms of Deprivation and Well-Being on the Basis of Some Significant Heterogeneity Factors}

We will now consider patterns of socio-economic differentiation in relation to cluster composition and membership, or, in other words, the extent to which age, level of

Table 3 Description of the 9 macro-clusters using an alphanumeric code

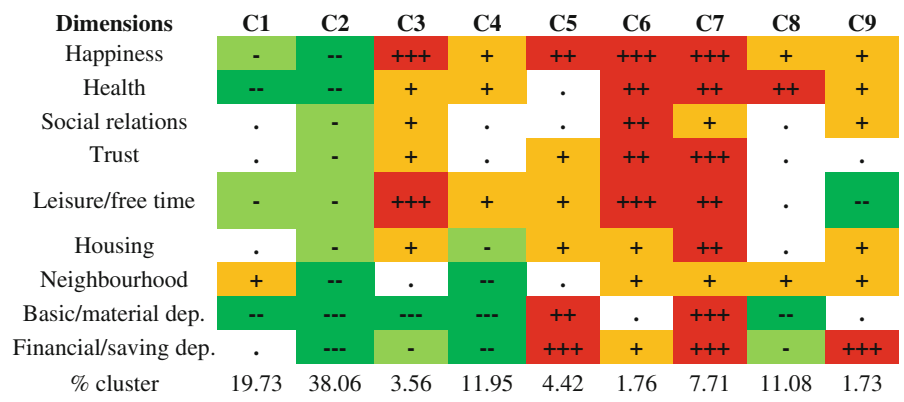


education, economic poverty and region of residence contribute to predicting the composition and the risk of membership to the 9 identified clusters. Looking at these simple bivariate statistics, we want to understand if traditional forms of stratification continue to play a crucial role in accounting for patterns of multiple deprivation and well-being, or if, on the other hand, these properties have lost their structural strength (Table 4).

As might have been expected, age seems to be a factor that plays a crucial role in the structuring of inequality. It is not surprising that clusters 8 and 9 , which express forms of deprivation related to ill health, record a higher average age than the other structures (55-56 years). The youngest clusters are numbers 3 and 5 (with an average age of 41 years), which attract people who tend to be unhappy, with little free time, and who lack trust in the institutions. Moreover, cluster 5 differs from cluster 3 due to the severe economic deprivation recorded.

An examination of the percentage of poor people in each cluster reveals a systematic pattern of variation. In clusters 5 and 7, marked by severe forms of economic deprivation, the percentages of poor people amount to 32 and $40 \%$ respectively, while in clusters 2,3 and 4 this category records the lowest levels, $<7 \%$.

In conclusion, cluster 7 (multidimensional deprivation) contains a very low percentage of university graduates $(7 \%$ ), while in cluster 2 (cumulative well-being), and in cluster 3 (people who are economically affluent but unhappy), respectively 20 and $22 \%$ of people have university degrees.

In general, poverty rates and low educational levels are good predictors of the condition of economic and multidimensional deprivation.

Moreover, an examination of the cluster profile, or, in other words, the probability of belonging to individual clusters as a result of socio-demographic factors, produces very interesting results (Table 5).

Those aged more than 65 have a probability of belonging to cluster 8 (ill health) that is approximately $14 \%$ points higher than those aged 25 or less. Conversely, people aged between 26 and 65 record a relatively greater probability of belonging to the cumulative wellbeing cluster.

The level of education and the head count ratio prove to be good predictors of belonging to the multiple wellbeing cluster, and, in a complementary manner, of not belonging to the cumulative deprivation cluster. $47 \%$ of university graduates belong to cluster 2 (multidimensional wellbeing), versus $36 \%$ of non-graduates. On the other hand, only $3 \%$ of graduates belong to the multidimensional deprivation cluster (No. 7), versus $9 \%$ of nongraduates.

Table 4 Composition of SOM clusters by mean age, percentage of poor and percentage of tertiary education
OECD-scale; poverty line: $60 \%$ of median equivalent income

\begin{tabular}{llll}
\hline Clusters & Mean age & $\begin{array}{l}\operatorname{Pr}(\text { poorlnode }) \\
(\%)\end{array}$ & $\begin{array}{l}\text { Pr(tertiary educ. } \\
\text { Inode) }(\%)\end{array}$ \\
\hline 1 & 46.9 & 15.9 & 14.8 \\
2 & 47.1 & 6.9 & 20.1 \\
3 & 41.8 & 6.7 & 22.2 \\
4 & 45.4 & 5.4 & 17.1 \\
5 & 41.4 & 31.7 & 10.3 \\
6 & 43.1 & 11.9 & 12.4 \\
7 & 49.2 & 39.6 & 7.0 \\
8 & 55.5 & 14.2 & 12.7 \\
9 & 56.6 & 23.0 & 10.7 \\
\hline
\end{tabular}


The probability of belonging to cluster 2 (multidimensional wellbeing) is $21 \%$ points higher for those situated above the economic poverty threshold than for those situated below it. The probability of belonging to cluster 7 (multidimensional deprivation) is $18 \%$ points higher for those situated below the threshold than for those situated above it. Substantial differences in terms of percentage points can also be found regarding the probability of belonging to clusters 4 and 5 .

In conclusion, the proportion of people living in a situation of cumulative deprivation (cluster 7) is definitely greater in the Lake Geneva Region than elsewhere. More specifically, $14.6 \%$ of Lake Geneva residents belong to cluster 7, versus $4.4 \%$ for the NorthWest Switzerland region.

In general, it can be said that the main social collocation variables-age, level of education, head count ratio and region of residence-make a significant impact on the possibility of enjoying living levels that can be described as high or deprived, to varying degrees. This evidence seems to agree more with the theory of the crystallisation of social inequalities rather than with the theory of the individualisation of life paths.

Moreover, an attentive observer will not fail to note that there is not a complete overlap between the head count ratio, which is one of the most popular monetary measurements of poverty quantification, and the life conditions identified on the basis of a wide range of non-monetary indicators. On the contrary, it can be said that the presence of people with income levels below the poverty threshold among the groups that are in situations of full wellbeing represents a re-test of the limits of the monetary measurements in identifying real states of deprivation. At the same time, the fact that so many people who are not economically poor are found in groups of strong cumulative deprivation highlights the propensity of this measurement to over-estimate the effective living levels of people interviewed.

Table 5 Profile of SOM clusters by mean age, education, poverty condition and percentage of tertiary education

\begin{tabular}{llllllllllll}
\hline & $\mathrm{c1}$ & $\mathrm{c} 2$ & $\mathrm{c3}$ & $\mathrm{c} 4$ & $\mathrm{c5}$ & $\mathrm{c6}$ & $\mathrm{c7}$ & $\mathrm{c} 8$ & $\mathrm{c} 9$ & Total \\
\hline Until 25 years old & 21.53 & 36.59 & 4.82 & 12.47 & 8.12 & 1.18 & 7.29 & 6.82 & 1.18 & 100 \\
$26-45$ & 20.7 & 39.38 & 4.52 & 13.18 & 5.12 & 2.89 & 6.81 & 6.54 & 0.87 & 100 \\
46-65 & 17.4 & 40.53 & 3.45 & 12.11 & 3.02 & 1.49 & 8.35 & 12.07 & 1.57 & 100 \\
Older than 65 & 21.77 & 31.13 & 0.92 & 8.85 & 3.15 & 0.81 & 8.24 & 20.96 & 4.17 & 100 \\
Less than tertiary EDUC & 20.06 & 36.31 & 3.31 & 11.82 & 4.73 & 1.84 & 8.56 & 11.54 & 1.84 & 100 \\
Tertiary EDUC & 18.03 & 47.15 & 4.87 & 12.64 & 2.8 & 1.35 & 3.32 & 8.7 & 1.14 & 100 \\
No-poverty & 19.01 & 40.96 & 3.88 & 13.01 & 3.44 & 1.78 & 5.36 & 11.01 & 1.54 & 100 \\
Poverty & 23.46 & 19.79 & 1.83 & 4.85 & 10.5 & 1.57 & 23.1 & 11.93 & 3.01 & 100 \\
Lake Geneva & 22.52 & 26.41 & 4.17 & 8.83 & 7.28 & 2.72 & 14.6 & 11.36 & 2.14 & 100 \\
Middleland & 21.2 & 36.06 & 3.66 & 11.45 & 5.04 & 1.96 & 7.33 & 11.06 & 2.23 & 100 \\
North-west Switzerland & 16.78 & 43.61 & 3.42 & 15.64 & 3.2 & 1.37 & 4.45 & 10.39 & 1.14 & 100 \\
Zurich & 18.15 & 40.83 & 4.05 & 11.87 & 2.9 & 2.03 & 6.95 & 12.07 & 1.16 & 100 \\
East Switzerland & 16.15 & 45.59 & 2.31 & 13.7 & 3.66 & 0.68 & 5.43 & 10.18 & 2.31 & 100 \\
Central Switzerland & 20.07 & 43.37 & 2.51 & 12.01 & 3.05 & 0.9 & 6.45 & 10.57 & 1.08 & 100 \\
Ticino & 27.75 & 31.94 & 5.24 & 9.42 & 4.71 & 2.09 & 5.24 & 12.57 & 1.05 & 100 \\
Total & 19.73 & 38.06 & 3.56 & 11.95 & 4.42 & 1.76 & 7.71 & 11.08 & 1.73 & 100 \\
\hline
\end{tabular}




\section{Conclusions}

In this paper the aim was to capture the multiple forms of deprivation and well-being in Switzerland, using an innovative approach of data reduction-Self Organizing Map (SOMs) - which can overcome the limitations of standard approaches to poverty and inequalities, which involve minimal assumptions and arbitraries.

As mentioned in the theoretic section, in the last 30 years social researchers have become increasingly interested in developing multidimensional measures of well-being, social exclusion and deprivation, in order to overcome the limitations of the standard income poverty measures. Unfortunately, the more recent approaches to the analysis of well-being and deprivation also stick to macro variables (i.e. Human Development Index) or to synthetic measures obtained by collapsing a certain number of items into a synthetic indices. Our approach, on the other hand, is intended to produce a segmentation of individuals in terms of a wide range of indicators of well-being and deprivation, without weighting these indicators and without collapsing them into synthetic measures in order to preserve the multidimensionality of the input data as much as possible.

The results trace out a complex and highly informative picture of the disparities in life possibilities in contemporary Switzerland, by referring to a large number of aspects, or dimensions, ranging from the health and happiness of those interviewed, to the availability of material goods and financial resources, to the housing situation, the quality of interpersonal relationships, trust toward other people and toward the institutions, ways in which to enjoy free time and the conditions of the housing and of the surrounding environment.

Summarising the most significant results of our taxonomy, at one extreme we find $38 \%$ of people in a condition of cumulative well-being, versus $7 \%$ of citizens who are in a condition of multiple deprivation. Forms of intermediate vulnerability stand out among these extreme social categories, and they are of considerable interest to any policy maker wishing to plan public policies aimed at segments of the population marked by an assembly of life possibility indicators. Cluster 8 , which contains people who are economically affluent but in bad health, and cluster 3, which includes people who are deprived on all except the financial dimension, would be difficult to intercept using traditional measures based on monetary indicators. This model is clearly limited by the fact that it cannot be used for comparative and longitudinal analyses.

Secondly, we have corroborated the existence of a significant statistical association between the multidimensional clusters and some traditional factors of social heterogeneity-age, level of education, poverty, region of residence-which leads us to consider the theory of social stratification to be one that responds most closely to the empirical evidence, rather than the opposing approach adopted by the theory of life path individualisation. Moreover, it is worth bearing in mind that although the head count ratio is a good predictor of economic-financial deprivation, it is far from constituting a reliable alternative for the wellbeing conditions of people, understood in multidimensional terms and derived by means of a series of non-monetary, quality of life indicators.

In conclusion, we firmly believe that these clustering procedures applied to non-monetary indicators constitute a useful supplementary tool to the traditional, monetary measurements, since they can produce a more comprehensive and organic picture of the plurality of people's life conditions, and of their effective means of accessing the economic, social and relational resources that allow them to make autonomous choices regarding their individual existence models. 
Acknowledgments This study has been financed by the Swiss National Science Foundation (Grants 00017_138033/1).

\section{References}

Alesina, A., Di Tella, R., \& McCulloch, R. (2002). Inequality and happiness: Are Europeans and Americans different? Harvard: Mimeo.

Allardt, E. (1976). Dimensions of welfare in a comparative Scandinavian study. XIX: Acta Sociologica. 3.

Andrews, F. M., \& Withey, S. B. (1976). Social indicators of well-being. Americans' perceptions of life quality. New York: Plenum Press.

Atkinson, T. (1987). On the measurement of poverty. Econometrica, 55, 749-764.

Atkinson, T. (2000). La povertà in Europa. Bologna: il Mulino.

Berghman, J. (1995). Social exclusion in Europe: Policy context and analytical framework. In G. Room (Ed.), Beyond the threshold. The measurement and analysis of social exclusion (pp. 19-28). Bristol: The Policy Press.

Bourdieu, P. (1980). Le capital social: Notes provisoires. Actes de la Recherche en Sciences Sociales, 31, $2-3$.

Brandolini, A., \& D’Alessio, G. (2002). Measuring well-being in the functioning space. Conference at on Hügel Institute. St Edmund's College, University of Cambridge.

Brown, S. L. (2004). Family structure and child well-being: The significance of parental cohabitation. Journal of Marriage and Family, 66, 2.

Budowski, M., Tillmann, R., \& Bergman, M. (2002). Poverty, stratification, and gender in Switzerland. Swiss Journal of Sociology, 28(2), 297-317.

Burchardt, T., Le Grand, J., \& Piachaud, D. (2002). Degrees of exclusion: Developing a dynamic, multidimensional measure. In J. Hills, J. Le Grand, \& D. Piachaud (Eds.), Understanding social exclusion (pp. 30-43). Oxford: Oxford University Press.

Byrne, D. (1999). Social exclusion. Buckingham: Open University Press.

Callan, T., \& Nolan, B. (1991). Concepts of poverty and the poverty line: A critical survey of approaches to measuring poverty. Journal of Economic Surveys, 5, 243-262.

Cantril, H. (1965). The pattern of human concerns. New Brunswick: Rutgers University Press.

Castel, R. (1995). Les méthamorphoses de la question sociale. Paris: Fayard.

Castel, R. (1997). Disuguaglianze e vulnerabilità sociale. Rassegna Italiana di Sociologia, 1, 41-56.

Coleman, J. (1990). Foundations of social theory. Cambridge: Harvard University Press.

De Wilde, C. (2004). The multidimensional measurement of poverty in Belgium and Britain: A categorical approach. Social Indicators Research, 68, 331-369.

De Wilde, C. (2008). Multidimensional poverty in Europe: Institutional and individual determinants. Social Indicators Research, 83, 233-256.

Easterlin, R. A. (2001). Income and happiness: Towards an unified theory. Economic Journal, Royal Economic Society, 111(473), 465-484.

Ferro Luzzi, G., Flückiger, Y., \& Weber, S. (2008). A cluster analysis of multidimensional poverty in Switzerland. In N. Kakwani \& J. Silber (Eds.), Quantitative approaches to multidimensional poverty measurement (pp. 63-79). London: Palgrave MacMillan.

Frey, B., \& Stutzer, A. (2002). Happiness in economics. Princeton: Princeton University Press.

Fuentes, N., \& Rojas, M. (2001). Economic theory and subjective well-being: Mexico. Social Indicators Research, 53(3), 289-314.

Fukuyama, F. (1995). Trust: The social virtues and the creation of prosperity. New York: Free Press.

Gambetta, D. (1998). Trust: Making and breaking cooperative relations. Oxford: Basil Blackwell.

Gazareth, P., \& Suter, C. (2010). Deprivation and risk of impoverishment in Switzerland, 1999-2007. Swiss Journal of Sociology, 36(2), 213-234.

Glatzer, W., \& Zapf, W. (1984). Die Lebensqualität der Bundesbürger. Politik und Zeitgeschichte, B44, $3-25$.

Haller, M., \& Hadler, M. (2006). How social relations and structures can produce happiness and unhappiness: An international comparative Analysis. Social Indicators Research, 75(2), 169-216.

Halleröd, B. (1995). The truly poor: Indirect and direct consensual measurement of poverty in Sweden. Journal of European Social Policy, 2(5), 111-129.

Heinzmann, C., \& Bergman, M. M. (2010). Social exclusion and poverty between theory and empiricism: Mapping two social science constructs. Swiss Journal of Sociology, 36(3), 511-539.

Kahneman, D. (2007). Economia della felicità. Milano: Il Sole 24 Ore Pirola. 
Kohonen, T. (1982). Self-organized formation of topologically correct feature maps. Biological Cybernetics, 43, 59-69.

Kohonen, T. (2001). Self-organizing maps. Berlin: Springer.

Layte, R., \& Whelan, C. T. (2002). Moving in and out of poverty: The impact of welfare regimes on poverty dynamics in the EU. The Economic and Social Research Institute, University of Essex: EPAG Working Paper, 2002-2030.

Lucchini, M., Pisati, M., \& Schizzerotto, A. (2007). Stati di deprivazione e di benessere nell'Italia contemporanea. Un'analisi multidimensionale. In A. Brandolini \& C. Saraceno (Eds.), Povertà e benessere. Una geografia delle disuguaglianze in Italia (pp. 271-303). Bologna: il Mulino.

Luhmann, N. (1979). Trust and power. New York: Wiley.

Martinez, R., \& Huerta, J. R. (2004). Income, multiple deprivation and poverty: An empirical analysis using Spanish data. Working paper prepared for the 26th general conference of the international association for research in income and wealth, Cracow, Poland, 27 August to 2 September.

Moiso, P. (2005). A latent class application to the multidimensional measurement of poverty. Quantity and Quality, 38(6), 703-717.

Muffels, R., \& Fouarge, D. (2003). The role of European welfare states in explaining resources deprivation. The Economic and Social Research Institute, University of Essex: EPAG Working Paper, 2003-2041.

Mutti, A. (1998). Capitale sociale e sviluppo. La fiducia come risorsa. Bologna: il Mulino.

Negri, N. (1990). Saggi sull'esclusione sociale. Povertà, malattie, cattivi lavori e questione etnica. Torino: il Segnalibro.

Nolan, B., \& Whelan, C. T. (1996a). Resources, deprivation and poverty. Oxford: Clarendon Press.

Nolan, B., \& Whelan, C. T. (1996b). Measuring poverty using income and deprivation indicators: Alternative approaches. Journal of European Social Policy, 6, 225-240.

Paugam, S. (Ed.). (1996). L'exclusion. L'état des savoirs. Paris: La Decouverte.

Pisati, M., Whelan, C. T., Lucchini, M., \& Maitre, B. (2010). Mapping patterns of multiple deprivation using self-organising maps: An application to EU SILC data for Ireland. Social Science Research, 39(3), 405-418.

Putnam, R. D. (1993). The prosperous community: Social capital and public life. American Prospect, 4, 13.

Ringen, S. (1988). Direct and indirect measures of poverty. Journal of Social Policy, 17, 351-366.

Runciman, W. G. (1966). Relative deprivation and social justice. London: Routledge.

Saraceno, C. (1990). Nuove povertà o nuovi rischi di povertà? In N. Negri (Ed.), Povertà in Europa e trasformazione dello stato sociale (pp. 249-276). Milano: Franco Angeli.

Saraceno, C. (Ed.). (2002). Rapporto sulle politiche contro la povertà e l'esclusione sociale 1997-2001. Commissione d'indagine sull'esclusione sociale. Roma: Carocci.

Scitovsky, T. (1976). The Joyless economy: An inquiry into human satisfaction and consumer dissatisfaction. New York: Oxford University Press.

Sen, A. (1981). Poverty and famines: An essay on entitlement and deprivation. Oxford: Clarendon Press.

Sen, A. K. (1985). Commodities and capabilities. Amsterdam: North Holland.

Sen, A. (2000). Social justice and the distribution of income. In A. B. Atkinson \& F. Bourguignon (Eds.), Handbook of income distribution (Vol. 1, pp. 59-85). Oxford: Elsevier.

Suter, C., \& Iglesias, K. (2005). Relative deprivation and well-being: Switzerland in a comparative perspective. In H. Kriesi, P. Farago, M. Kohli, \& M. Zarin-Nejadan (Eds.), Contemporary Switzerland: Revisiting the special case. New York: Palgrave Macmillan.

Suter, C., \& Paris, D. (2002). Ungleichheit und deprivation: Die Schweiz im Drei-Länder-Vergleich. Swiss Journal of Sociology, 28(2), 217-240.

Tillmann, R., \& Budowski, M. (2006). La pauvreté persistante: Un phénomène de classe, de cumul de désavantage ou d'individualisation? Revue swisse de sociologie, 32(2), 329-348.

Walker, A., \& Walker, C. (1997). Britain Divided: The growth of social exclusion in the 1980s and 1990s. London: Child Poverty Action Group.

Whelan, C. T., Layte, R., \& Maître, B. (2002). Income and deprivation approaches to the measurement of poverty in the European Union. In R. J. A. Muffels (Ed.), Social exclusion in European Welfare States. Cheltenham: Edward Elgar.

Whelan, C. T., Lucchini, M., Pisati, M., \& Maitre, B. (2010). Understanding the socio-economic distribution of multiple deprivation: An application of self-organising maps. Research in Social Stratification and Mobility, 28(3), 325-342.

Whelan, C. T., \& Maître, B. (2005). Economic vulnerability, multi-dimensional deprivation and social cohesion in an enlarged European Union. International Journal of Comparative Sociology, 46, 215-239.

Whelan, C. T., \& Maître, B. (2007). Levels and patterns of multiple deprivation in Ireland: After the Celtic Tiger. European Sociological Review, 23, 139-156. 